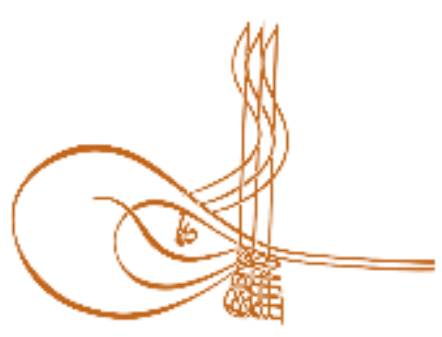

www.turkishstudies.net/social
Turkish Studies-Social Sciences

eISSN: $2667-5617$

Research Article / Araştırma Makalesi

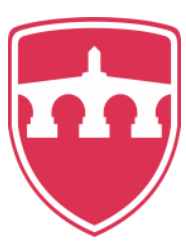

INTERNATIONAL BALKAN

UNIVERSITY

Sponsored by IBU

\title{
Konya Âşıılar Bayramı ve 53.Konya Âşıklar Bayramı'nda Mevlana Meydanı'nda Düzenlenen Programda İcra Edilen Âşıklık Geleneğindeki Türler
}

\author{
Konya Lovers' Dayand 53.Typesin TheTradition of MinstrelsyPerformedin the Program Heldin \\ Mevlana SquareDuringthe Konya Minstrel Festival
}

\author{
Ramazan Kamiloğlu*
}

\begin{abstract}
In this study, while the last celebrations of Konya Lovers' holiday, which has been going on for fifty-three years, is started, the works related to the minstrel tradition performed at the ceremonies held in Mevlana Square were recorded and evaluated. By continuing the fifty-third Konya 'Lovers' Festival, the continuing tradition was maintained. Many lovers who participate have economic difficulties because they do not have a regular job to earn income. Economic conditions need to be improved in order to increase the participation in the Minstrel Feast. It has been in love with the participation of the various parts of Turkey Konya lovers but they provide less participation. Encouraging activities should be done for more participation. Cultural activities are decreasing day by day and there are obstacles in transferring the tradition of minstrelship to future generations. One of these obstacles is that the minstrel tradition is not adequately promoted and recognized. Especially, the local administrations' employment and the duties they will give will be effective in this way. It will be effective for public and continuous demonstrations to be held in public by providing venues where lovers can perform in each province and district. In primary, secondary and high school schools, students can organize and watch programs about the promotion of lovers. The participation list was given by stating the lovers and pseudonym participating in the Fifty Third Lovers Day. We have given examples of competitions, poetry, coaching and folk songs in Mevlana Square. If such meetings and great participation of the lovers are provided, it will contribute to Turkish Literature, folk songs and peace of society. Moreover, by carrying these festivals to an international level, it is possible to strengthen the brotherhood and unity by providing participation from all over the Turkish World.
\end{abstract}

Structured Abstract: Inthisstudy, were cordedand evaluated the work related to the tradition of minstrelsy performed at ceremoniesheld in Mevlana Square as the last celebrations of Konya minstrel holiday, which has been going on for fifty-three years. We gave the list of participants by specifying the lover sand their mahlas who participated in the fifty-third lovers ' holiday. Examples of fights, poetry, koçaklama and folk songs were given in Mevlana Square

\footnotetext{
*Dr. Öğr. Üyesi, İnönü Üniversitesi, Devlet Konservatuvarı, Müzik Bölümü Asst. Prof. Dr. Inonu University, Conservatoire, Department of Music ORCID 0000-0003-4855-1840 ramazan.kamiloglu@inonu.edu.tr Cite as/ Atıf: Kamiloğlu R. (2020). Konya Âşıklar Bayramı ve 53. Konya Âşıklar Bayramı’nda Mevlana Meydanı'nda düzenlenen programda icra edilen âşıklık geleneğindeki türler, TurkishStudies - Social, 15(3), 11851201. https://dx.doi.org/10.29228/TurkishStudies.40466

Received/Geliş: 08January/Ocak 2020

Accepted/Kabul: 25 April/Nisan 2020

Checked by plagiarism software

Copyright $($ INTAC LTD, Turkey

Published/Yayın: 30 April/Nisan 2020

CC BY-NC 4.0
} 
53. Lovers 'Day under the name of the love of homeland Konya Lovers' Day great efforts and contributions to the memory of Feyzi Halıc and Ali Berat Alptekin on October 23, 2019, Mayor of Karatay Hasan Kılcan'nın Karatay Municipality in front of the pres statement was started. Öksüz Ozan, Yağız Ozan and Aş1k Aliyar have started a feast of lovers with examples of a throw and a coaching. However, the main program of the festival of lovers was held in the Mevlana Culture Center on 24-25 October. During the day, programs in the nature of prepara tory programs were held in different squares of Konya. In this study, we will take a short look at the minstrel tradition in Konya and the beginning of the minstrel feast in Konya before proceeding to evaluate the minstrel examples performed in the program in Konya.

Seljuk Konya continued to be the presence of minstrels playing bards. The current lovers have been working on the path of the popular voice that has been going on for centuries. "Ozan" is the Turkish word from Oguz Khan, which means that Oguz Ata is the lover who reads the epics by playing kopuz.

Insome of the meetings we attended in the coffee lovers' conversations, we were old that the poet meant stealing master's good sand the lover me ant improvising. However, according to the above statement, we can say that both have the same meaning.

Enthusiastic lovers have never been missing in Konya. In the 17th century, Âş1k Ömer later took the instrument of Koca Ahmet and wandered the landand went to Kerbelâ duetto his devotiontoImam Yahya. Cemalî, Cevlanî, Feşanî, Gufranî, Hasan Hüseyin, Hikmetî, Kemterî, Kenzî, Lokmanî, Merdanî, Rıza Efendi, Aşık Mehmet, Şevkî, especially III. Selim's appreciation and appreciation of themaster in lovewithŞem'î, II. Both of ourlovers, Silleli Sururi, who took aim from Abdu'l-Hamit Khan, played folk musicand folk songs in thepalaceboth in thepalaceand in thepublic. Inthelight of this information, we can say that in addition to Classical Turkish Music, Turkish Folk Music was also performed in thepalace.

In our interviews with Aşık Nuri Şahinoğlu, he stated that Aşık Dertlî had been in love with juicy coffee for twenty years. In addition, the grave of Âşık Şem'in Mevlana mausoleumand Üçler Cemetery on the way to the current Mevlana Cultural Center, the only grave on the way to specify that the minstrel belongs to Aşık Şem'i, in 1960, the governor of Konya Cahit Besilinin wanted to eliminate the tomb to expand the road, but despite all the work the governor, who saw that digging in the grave did not work, saidt hat his right arm was paralyzed when he took the digging and hit himself on the grave. Since Üçler cemetery has a largearea, we believe that the grave of Âşık Şemi may have been separated from the cemetery of Üçler. Because Mehdi Halıcı stated in his book Konya Sazı and Türküleri that the tomb of Şemi was in the cemetery of thethree.

With the information given by the orphan Bard (Öksüz Ozan), the following products of the Aş1k tradition were processed at the previous lovers ' holidays: Atışma, guzeleme, koçaklama, divan, leb değmez, türkü, Storyful folk song, humorous folk song, humorouspoetry, muamma, teclis, musammat.

Public interest in the program sheld in various squaresand Mevlana Cultural Center of Konya was very intense. Minstrels ' skillful execution of the types they perform has made the minstrel tradition to be loved and interested. The lovers performed very well on the programmes with no self-assure dexcitement. They had a very good dialogue and conversation with each other. Their that ched verbal squabbles had over flowed into loungesand hotels where they were resting. The brotherhood among lovers from different parts of Turkey was almost like a sign of all Turkey. If the se holidays are replicated in allregions of Turkey by taking the example of Konya, the participation of lovers in all regions can be ensured.

In line with the information given by the orphan Bard (Oksuz Ozan), the following products of the Asık tradition were processed at the previous lovers ' holidays: Atışma, guzeleme, koçaklama, divan, leb degmez, türkü, storyful folk song, humorous folk song, humorouspoetry, muamma, teclis, musammat, satire.

We believe that if such lovers' meetings and great participation are provided, they will contribute to Turkish literature, folk songs and community peace. Infact, if we take these festivals to an internationallevel, ifthere is participation from all sides of the Turkish World, the brotherhood and unity between us can be strengthened.

Keywords: Konya, Asik, maidan, ceremony, folk song. 
Öz: Bu çalışmada elli üç yıldır devam ede gelen Konya Âşsklar Bayramı’nın son kutlamaları başlarken Mevlana Meydanı'nda düzenlenen törenlerde icra edilen âşıklık geleneğiyle ilgili çalışmaların kayıt altına alınarak değerlendirmesi yapılmıştır. Elli üçüncü Konya Âşıklar Bayramı'nın yapılmasıyla süregelen geleneğin devamı sağlanmıştır. Katılım sağlayan pek çok âşık, gelir elde edebilecekleri düzenli bir işe sahip olmadığı için ekonomik zorluklar çekmektedir. Âşıklar Bayramı'na katılımın artırılması için ekonomik şartların iyileştirilmesi gerekmektedir. Türkiye'nin çeşitli yerlerinden âşıkların katılımı olmuştur ancak Konyalı âşıklar daha az katılım sağlamıştır. Daha fazla katılım için de teşvik edici çalışmaların yapılması gerekmektedir. Günden güne kültürel etkinlikler azalmaktadır ve özellikle âşıklık geleneğinin gelecek nesillere aktarılması hususuna engel olmaktadır. $\mathrm{Bu}$ engellerin başlıca nedenleri; âşıklık geleneğinin yeterince tanıtılmaması ve tanınmamasıdır. Özellikle yerel yönetimlerin, âşıkların istihdamına katkı sağlamak için vereceği görevler bu yolda etkili olacaktır. Her ilde ve ilçede âşıkların gösteri yapabileceği mekânlar sağlanarak halka açık ve sürekli gösteriler yapılması bu bağlamda etkili olacaktır. İlköğretim, ortaöğretim ve lise öğrencilerine âşıkların tanıtımıyla ilgili programlar düzenlenip izletilmesi de bu geleneğin daha çok tanınmasına vesile olacaktır. Elli üçüncü Âşıklar Bayramı'na katılan âşıklar ve mahlasları belirtilerek katılım listesi verilmiştir. Mevlana Meydanı'nda atışmalara, şiire, koçaklamaya ve türküye örnekler verilmiştir. Âşıkların bu tür buluşmalarıyla beraber yoğun katılımların sağlanmasının; Türk Edebiyatı'na, Türkülere ve toplum barışına oldukça katkısı olacaktır. Hatta bu bayramların uluslararası bir düzeye taşınmasıyla da Türk Dünyasının her yerinden katılım sağlanmasına vesile olunarak kardeşliğin ve birliğin kuvvetlendirilmesi sağlanabilir.

Anahtar Kelimeler: Konya, âşık, meydan, tören, türkü

\section{Giriş}

53. Âşıklar Bayramı vatan aşkıyla, Konya Âşıklar Bayramı'na büyük emekleri ve katkıları olan Feyzi Halıcı ve Ali Berat Alptekin anısına 23 Ekim 2019 da Karatay Belediye Başkanı Hasan Kılcanın Karatay Belediyesi önündeki basın açıklamasıyla başlatılmıştır. Öksüz Ozan, Yağız Ozan ve Âşı1k Aliyar'ın bir atışma ve bir koçaklama örnekleriyle Âşıklar Bayramı devam etmiştir. Ancak Âşıklar Bayramı'nın esas programı 24 -25 Ekim akşamları Mevlana Kültür Merkezi'nde yapılmıştır. Gündüzleri ise Konya'nın değişik meydanlarında halk arasında hazırlık mahiyetinde programlar yapılmıştır. Bu çalışmamızda Konya Mevlana Meydanı'nda yapılan programda icra edilen âşıklık örneklerini değerlendirmeye geçmeden önce Konya'daki âşıklık geleneğine ve Konya Âşıklar Bayramı'nın başlangıcına kısaca göz atılacaktır.

\section{Konya'da âşııkık geleneği}

Selçuklu Konya'sında kopuz çalan ozanların varlığ 1 sürekli devam etmiştir. Şimdiki âşıklar da asırlardan beri süre gelen halk sesinin yolunda yürüyüp uğrunda çalışmaktadırlar (Gazimihal, 1947, s: 45). "Ozan" Oğuz Han kelimesinden Türkçeleşmiştir ki; Oğuz Ata destanlarını kopuz çalarak okuyan diyar diyar gezen âşık anlamına gelmektedir (Gazimihal, 1947, s: 45).

Âşıklar kahvelerinde katıldığımız bazı toplantılarda yaptığımız sohbetlerde ozanın usta malı çalıp söyleyen anlamına geldiğini, âşığın ise doğaçlama çalıp söyleyen anlamına geldiğini söylemektedirler. Ancak yukarıdaki ifadeye göre ikisinin da aynı anlama geldiği söylenilebilmektedir.

Konya'da coşkun âşıklar hiçbir zaman eksik olmamıştır. 17. Asırda Âşık Ömer, daha sonra Koca Ahmet sazını eline alarak diyar diyar dolaşmış; İmam Yahya'ya bağl1lığından dolayı Kerbelâ'ya giderek orada vefat etmiştir (Gazimihal, 1947, s: 46). Cemalî, Cevlanî, Feşanî, Gufranî, Hasan Hüseyin, Hikmetî, Kemterî, Kenzî, Lokmanî, Merdanî, Rıza Efendi, Âşık Mehmet, Şevkî, özellikle III. Selim'in beğenisine ve takdirine mazhar olan usta âșı Șem'î, Gazimihal'in kitabında Şemsî olarak geçmektedir. Âşşk Şem'̂̂, II. Abdu'l-Hamit Han'dan nişan alan Silleli Sururî ile hem sarayda hem de halkın içinde sazlarını çalarak halk müziğini ve türkülerini sarayda icra etmişlerdir (Gazimihal,1947, s. 46). Bu bilgiler 1şığında sarayda Klasik Türk Müziği'nin yanı sıra Türk Halk Müziği' nin de icra edildiğini söyleyebilmekteyiz. 
Âşık Şem’î Konya'da yetişen, divanı olan bir şair ve çalıp söyleyen en güçlü saz âşı̆̆ıdır. Asıl adı Ahmet olan Şem'î’nin dedeleri Pir Esatoğlu Hacı Hüseyin Ağa olup mahalleleri bugün hâlâ bu adı taşımaktadır (Halıcı, 1985, s: 4). Âşık Şem'î hakkında bilimsel araştırmalar yapmış ve Konya kültürüne çok faydalı çalışmalar yapmış olan Fevzi Halıcı âşığımız ve şairimiz hakkında şu bilgileri vermiştir: Âşık Şem'i, baba mesleği olan helvacılığa önem vermemiş, çocukluk ve gençlik yıllarında özgür bir tutum içinde yaşamıştır. Onun göz ve gönül dünyasında bütün dileği ve amacı şiir, söz ve sazıdır. O dönemde Konya'da iki kahve vardır. Birisi türbe önünde Türbe kahvesi, diğeri buğday pazarıyla Lârende caddesinin kesiştiği köşede ki Ayakçı kahvesidir. Bu kahveler genç ve acemi âşıkların devam ettikleri ve yetiştikleri bir ocak, bir okul gibidir. Usta âşıkların saz çalıp şiir söyledikleri, atışma yaptıkları, karşılıklı muamma söyledikleri bu kahvede şehrin aydınları, esnafi, köylüsü toplanarak usta ve acemi âşıkların gösterilerini izlemişlerdir. İşte Âşık Şem'î bu kahvelerin sazıyla müdavimlerinden biri olmuştur. O yıllarda Türbe kahvesini Âşık Dertlî (1772- 1845) işletmiştir. Âşık Şem'î ile Dertlî kısa sürede can ciğger dost olmuşlardır. İki âşı̆̆ın dil ve gönül birliği ile renklenen ve güzelleşen türbe kahvesi sanata âşık olan Konyalıların sıcak ilgisiyle dolup dolup boşalarak, dinleyiciler her gün yeni bir sanat ziyafetiyle mest olmuşlardır. Bu sanat halkasına kısa zamanda Sille'li Âşık Sururî de katılmıştır. O yıllarda Mevlevî Dergâhı'nda Postnişin olarak Mehmet Hemdem Sait Çelebi bulunmuştur (1807-1859). Çelebi, manevi duyarlılı̆g 1 ve görevleri yanı sıra güzel sanatlara olduğu kadar saza, şiire ve musikiye düşkün, rint meşrep bir insandır. Türbe kahvesinin küçük ve anlam dolu havasına büyük ilgi duymuştur. Bu ilgi meyvelerini vermekte gecikmemiştir. Çelebi il merkezindeki konağında ve Meramdaki bağında türbe kahvesinin usta âşıkları Şem'i ve Dertlî’yi düzenlediği sanat ve müzik toplantılarına davet etmiştir. Her an âşıklara maddi ve manevi yardımlarını esirgemeyen Hemdem Sait Çelebi, basık ve karanlık olan türbe kahvesini yıktırıp yerine bol pencereli, aydınlık, büyük bir kahve yaptırmıştır. Kahvenin ortasına büyük bir havuz yerleştirmiştir. Mevlana Dergâhı'na getirilen Dutludaki tatlı sudan bu kahveye de su aktarılmıştır. Bu kahve Birinci Dünya Savaşı'nın sonuna dek "Sulu Kahve" adıyla halk edebiyatının en güzel örneklerini halka sunmaya devam etmiştir. "Bu kahveden nasibini alan nice saz âşığının yurt içine dağıldıklarını, İstanbul'a gidip ün kazandıklarını, padişahlara saz çalıp şiir söylediklerini görüyoruz" (Halıcı, 1985, s: 4-5).

Âşık Şem'i’yi çok beğenen III. Selim Han âşığa bir isteği olup olmadığını sordurunca Şem'i Konya ilinin baş havalalığını ister ve bu göreve getirilmiştir. Daha sonra da Çarşı A ğalığı görevine getirilmiştir. Konya sanat ve kültürüne büyük bir derinliği ve katkısı olan Âşsı Şem’i 1842 yılında vefat etmiştir. Üçler mezarlığına defnedilmiştir (Halıcı, 1985, s: 6).

Âşık Nuri Şahinoğlu ile yaptığımız görüşmelerde Âşık Dertlî’nin sulu kahvede yirmi sene Ser Âşıklık yaptığını söylemiştir. Ayrıca, Mevlana Türbesi ile Üçler Mezarlığı arsından geçen, şimdiki Mevlana Kültür Merkezine doğru giderken yol üzerindeki tek mezarın Âşık Şem'i’ye ait olduğunu belirterek, 1960'ta Konya valisi Cahit Besilinin yolu genişletmek için türbeyi ortadan kaldırmak istediğini, ancak tüm çalışmalara rağmen Tek Mezar'a kazmanın işlemediğini gören vali kazmayı alıp bizzat kendisi mezara vurunca sağ kolunun felç olduğunu söylemiştir. Üçler mezarlı̆g 1 geniş bir alana sahip olduğu için zamanla yapılan yol çalışmalarında Âşık Şem'inin mezarı üçler mezarlığından ayrılmış olabileceği kanaatindeyiz. Çünkü Mehdi Halıcı, Konya Sazı ve Türküleri adlı eserinde Şem'inin mezarının üçler mezarlığında olduğunu belirmiştir.

Özellikle Konya tavrında etkili olan bağlamayı çok ustaca çalan Çopur Ahmet'i de burada anmadan geçemeyeceğiz. Babası, Konya saz üstatlarından Çopur İsmail'in oğludur. Ancak Çopur Ahmet saz çalmada babasını geçmiştir. Beş altı sazın uyumlu sesini tek bağlamayla yapabilen iyi bir icracıdır. TRT saz sanatçısı ve hocası olan Osman Özdenkçi Ankara'da Konya türkülerini içeren bir plak dinler. Bu plakta en az 5-6 sazın bir araya gelip bu kadar uyumlu çalmasına hayret eder ve şöyle der; "biz radyoda bile 5-6 sazcı bir arada bu kadar düzgün bir uyum kuramadık. Bunlar nasıl uyum içinde çalıyorlar diye şaşırdım kaldım. Plağın üstüne baktım Çopur Ahmet yazıyor. Aradan bir süre geçti Ankara'nın denizciler caddesindeki Sümer Sineması eskiden tiyatro binasıydı. Orada Çopur Ahmet'in bir konseri var dediler. Bu saz ustasını yakından dinleyip görmek 
için ön sırada bir yer tuttum. Saati gelince konser başladı. Sahneye tek bir bağlama ile bir adam çıktı geldi. Ben bekledim ki sazcıları ardından gelsin. Hiç kimse gelmeyince çok şaşırdım. Çünkü çopur Ahmet sazını konuşturmaya başlayınca plakta dinlediğim ahengi buldum. Çopur Ahmet 5-6 sazın verdiği sesi tek bir bağlamayla verebiliyordu. Anladım ki tüm yeteneği tezenesindeymiş. Bütün sazlar düz çaldıkları hâlde Konya mızrabı bu kuralı aşmıştı. Konya tezenesinde bir aşağı iki yukarı vuruluyor böylece 5-6 sazın çıkardığı toplu ses elde edilebiliyordu. Ben program bitince kulise gittim kendimi tanıtarak radyoda halk müziği hocası olduğumu söyledim. Araştırmacıyım, bu nasıl tezenedir senin vurduğun? Şimdiye kadar bir benzerini duymadık, dedim." Daha sonra Osman Özdenkçi Çopur Ahmet'in düzen perdesini tutup yarım saat içerisinde Çopur Ahmet'in kendisine Konya mızrabını öğrettiğini ifade ederek 6 ay boyunca Konya mızrabını çalıştığını belirtmiştir (Halıcı, 1985, s: 8).

Konya tavrının özelliği son mızraptan sonra mızrabın üst tellere taktırılmasıdır. İki şekilde vuruşları vardır. Eserleri çalarken birinci şekli icra edilir, bazen mezur sonlarında ve bitişlerde de ikinci mızrap şekli icra edilir. Konya mızrabı şudur:
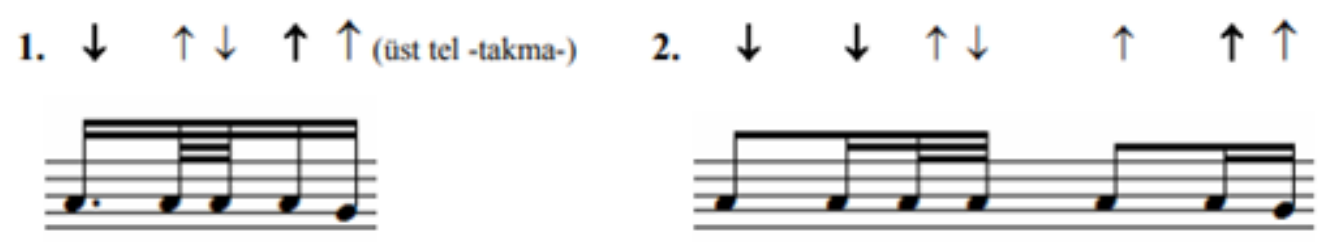

\section{Konya'da Âşıklar Bayramının Başlaması}

Feyzi Halıc1; halk sanatı, halk türküleri ve halk şiirinin temel kaynağının âşıklık geleneğinde yer aldığını ve bu geleneğin yaşatılmasına inandığı için Türkiye Âşıklar Bayramı'nı 1966 yılı 27 - 29 Ekim tarihlerinde yaklaşık 54 yıl önce Kültür ve Turizm Bakanlığımızın da katkıları ile ilk kez Konya'da başlatmıştır (Halıcı, 1985, s: 2). Daha sonra her yıl düzenlenen âşıklar bayramı Konya'da gelenek halini almıştır. Bu çalışmalarla Türkiye'deki âşıklar buluşturularak zengin bir türkü demeti oluşturulmuştur. Mehdi Halıcı, âşıklar bayramını " işin doğrusu biz Konya sazı ve türkülerinin değerini ve önemini işte bu bayramları yaparken anladık. Saz ve Halk Âşıklarına kucak açan Konya'nın bu zenginliğini gördük ve bu sanat güzelliğimizi tanıtmanın ne kadar yararlı olacağını düşündük" diyerek ifade etmiştir (Halıcı, 1985, s: 2). Konya'daki âşıklar bayramı her yere örnek olmuş ve daha sonra da Türkiye'nin birçok ilinde başlatılan gelenek günümüzde de devam etmektedir. Ancak uzun süre devamlılı̆̆ını sağlayan tek şılar bayramı Konya'da devam etmektedir.

\section{Konya Âşıklar Bayramı'nda âşıkların işledikleri türler}

Âşıklık geleneğinde işlenen türler, Türk Edebiyatı'ndaki Divan Edebiyatı ve Halk Edebiyatı çeşitlerinin nazım biçiminde olan ve sazla ya da sözle ifade edilen biçimleridir.

Divan: Hem aruz hem de hece ölçüsünün 11'li $6+5$ kalıbı ile âşıkların meydanlarda çalıp söylediği türdür (Sipahi, 1975, s: 144) şiirlerdir.

Atışma: Âşıkların karşılıklı olarak saz eşliğinde birbirlerine söyledikleri doğaçlama

Güzelleme: Saz şairlerinin doğa ve insan güzelliklerini öven sekizli hece vezni ile yazılıp söylenen şiirlerdir (Sipahi, 1975, s: 145).

Koçaklama: Halk Edebiyatında biçimi ne olursa olsun konusu yiğitlik, savaş ve kahramanlık olan şiirlerdir (TDK sözlük, s: 583). 
Taşlama: Kişi ve toplumdaki kusurlu ve gülünç yönleri alaycı ve iğneleyici bir biçimde işleyen öğretici bir şiir türüdür (Sipahi, 1975, s: 159).

Şiir: Zengin sembollerle, ritimli sözlerle, seslerin uyumlu kullanımıyla ortaya çıkan edebî anlatım biçimidir (TDK sözlüğ̈̈, 2000, s: 911).

Türkü: Türk'ye ait melodili şarkılardır, kuşaktan kuşağa aktarılan nağmeli şiirlerdir (Sipahi, 1975, s: 160- Özbek, 1994, s: 6).

Hikâyeli türkü: Öyküleriyle anlatılarak söylenen türkülerdir.

Lebdeğmez:"b, m, p, v" Harfleri gibi iki dudağın bir birine değmesiyle çıkan harfleri kullanmadan söylenen şiirlerdir.

Öksüz Ozanın verdiği bilgiler doğrultusunda daha önceki âşıklar bayramlarında da âşıklık geleneğinin şu türleri işlenmiştir: Atışma, güzelleme, koçaklama, divan, lebdeğmez, türkü, hikâyeli türkü, mizahi türkü, mizahi şiir, muamma, tecnis, müstezat, musammat, taşlama (hiciv).

\section{Konya Âşııklar Bayramına Katılan Âşııklar ve Mahlasları}

Ahmet Yildırım (Öksüz Ozan)

Nuri Cihan Karataş (Âşık Karataş)

Binali Kılıç (ÂşıkHüsrani)

Mürsel Sinan Uğursu(Âşık Mürsel Sinan)

Erol Aydın (Âşık Ergani)

Maksut Koca (Âşık Maksudi)

Ahmet Poyraz (Âş1k Poyrazoğlu)

Mehmet Köşe (ÂşıkKaptani)

Ali İhsan Öksüz (Maraşlı Öksüz Ozan)

Selahattin Kazan (ÂşıkKazanoğlu)

Eyüp Tadil (Âşık Eyyubi)

Ensar Şahbaz (Âşık Şahbazoğlu)

Ali Rıza Ezgi (Âşıłk Ali Rıza)

Muhlis Denizer (Âşık Muhlis)

Arif İnan Yıldırım (Yağız Ozan)

Bilal Ersari(ÂşıkLadiyaslı)

Muhsin Özen (Âşıłk Yaralı)

Zakir Tekgül(ÂşıkZakiri)

Selami Yağar (Âşık Selami Yağar)

Erzade Kapan (Âşık Erzade)

Gültekin Bulut (Aşık Bulutoğlu)

Behram Aktemur (ÂşıkBehrami)

Ensar İpek (Ensar İpekoğlu)

Zikri Alyar(Âşşk Zikri Aliyar) 
Zafer Kazancı (Âşık Zafer Kazancı)

\section{Mevlana Meydanı'ndaki Âşı̧ılar Programı}

Meydanlarda yapılan programların genelinde Öksüz Ozan hem sunuculuk yapıp hem de program içeriğine katkıda bulunmuştur. Öksüz Ozan'ın programı takdiminden sonra Âşık Zâkiri ile Âşık İpekoğlu'nun atışmalarıyla program başlamıştır. Ayağı Öksüz Ozan vermiştir "Ne âşıklar geldi geçti, 53 yıl bu meydanda". Atışmaya Âşık Zâkiri başlamıştır:

\section{Zâkiri:}

Ne âşıklar geldi geçti

53 yıl bu meydanda

Çobanoğlu Reyhâniler

53 yıl bu meydanda

İpekoğlu:

Oldular bizlere 1şı1k

53 y1l bu meydanda

Bülbül oldu güle âşık

53 yıl bu meydanda

\section{Zâkiri:}

Âşıkların budur derdi

Severim elbette merdi

Feyzi Halıcının derdi

53 y1l bu meydanda

İpekoğlu:

Hakka doğruydu dileği

Çelikten bükülmez bileği

Unutmadık geleneği

53 y1l bu meydanda

\section{Zâkiri:}

Zakirim şema döneriz

$\mathrm{Bu}$ aşka böyle yanarız

Yunus Mevlana anarız

53 y1l bu meydanda 
İpekoğlu:

İpekoğlu oldu zârı

Sizler çiçek bizler arı

Geleneğin ustaları

53 y1l bu meydanda

$\mathrm{Bu}$ atışmanın notası bu çalışmada örnek olarak alınmıştır. Başka bir çalışmada âşıkların gösterilerinin tamamının notaya alınması düşünülmektedir. Böylelikle aşıkların yeni söyledikleri türler kayıt altına alınmış olacaktır. 


\section{NE ÂŞIKLAR GELDİ GEÇTİ ELLİ ÜÇ YIL BU MEYDANDA}

SÖZ-MÜZIK: ÂSIK ENSAR İPEKOĞLU ÂȘIK ZÂKIR TEKGÜL
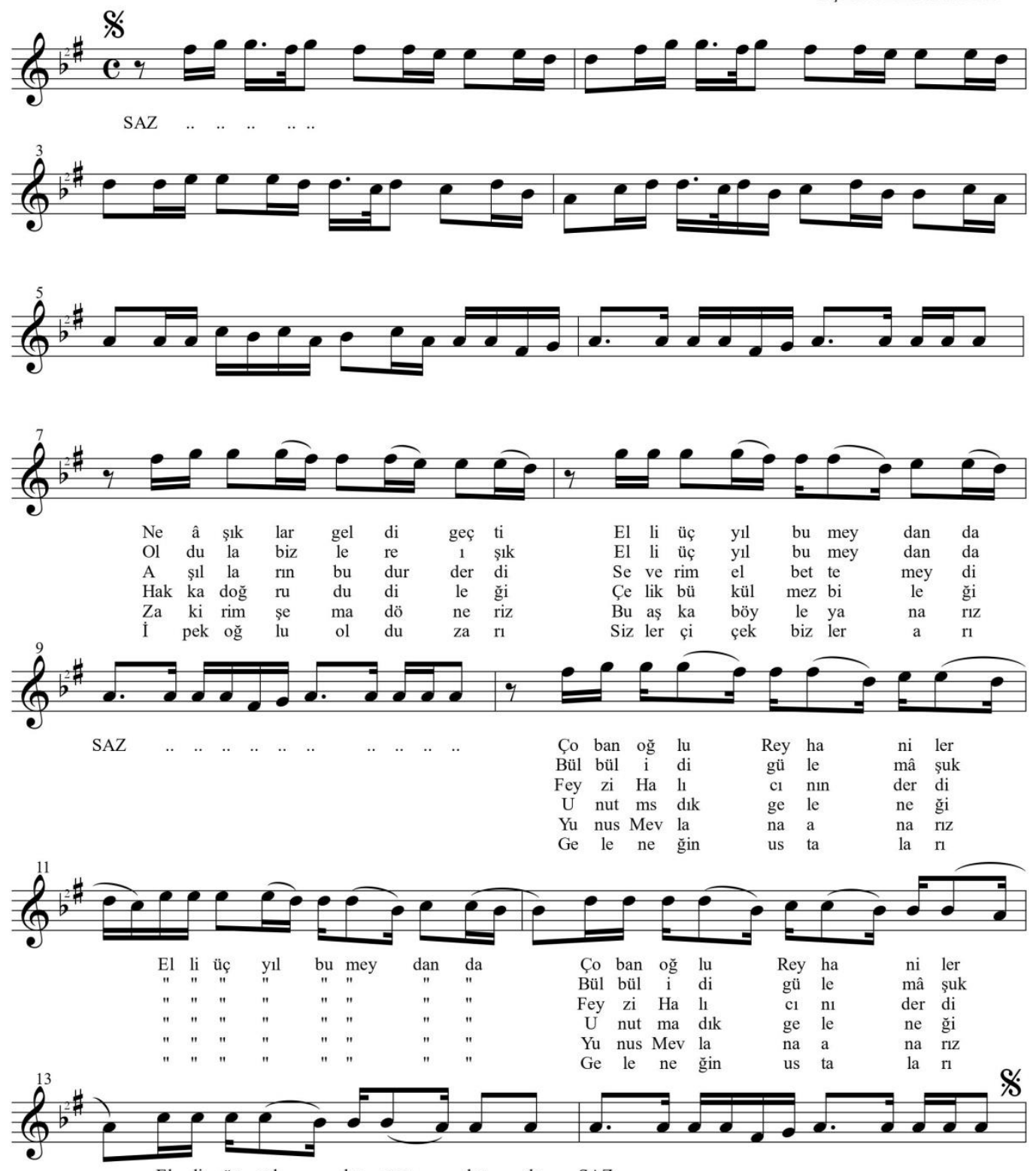

El li üç yil bu mey dan da SAZ 

edilmiştir:

Bu atışmadan sonra Âşık Selahattin Kazanoğlu bir şiir okuması için sahneye davet

\section{KORKMA}

Korkma, ey Türk Milleti bu duygu sana yasak

Korkma, dağılır duman elbet sökecek şafak

Korkma, senin tek arzun daima hür yaşamak

Korkma, sarp kayalara giren kartallar tüner

Korkma, tuzak kuranın tuzak kendine döner

Korkma, çağlayan Tuna Hazarda çalkalanır

Korkma, turan yurdunda al bayrak dalgalanır

Korkma, alperenlerin dalga dalga şahlanır

Korkma, dünkü düşmanlar senin sabrını sınar

Korkma, cesaretle bakan yıldız ve hilale

Korkma, destan dolusun şahidin Çanakkale

Korkma, yeter ki dik dur düşman şaşsın bu hale

Korkma, yanlış hesap elbet doğruya döner

Korkma, yalancinın mumu yatsıya olunca söner

Korkma, bu Kazan Oğlu özgür çalsın sazını

Korkma, sabır ile kır küfrün infazını

Korkma, samimice yap nazını niyazını

Korkma, ülkü yürekler bu hasret ile yanar

Korkma, kur Türkistan'1 ancak ruhumuz kanar.

Şiirden sonra Âşık Ergani bir koçaklama söylemek üzere sahneye davet edilmiştir, bir kıta şiir söyledikten sonra "Bekle Fırat Geliyoruz" isimli koçaklamayı söylemiştir:

Bıçak kemiğe dayandı

Bekle Firat geliyoruz

Geliyoruz geliyoruz

Yavaş yavaş alıyoruz 
Kahpe düşman ürdükçeür

Mehmet yiğit gücünü gör

Amaç huzur hedef terör

Bekle Firat geliyoruz

Geliyoruz geliyoruz

Biz Konya'dan geliyoruz

Yedi bölge yurdumuzla

Ozanımız merdimizle

Yenilmeyen ordumuzla

Bekle Frrat geliyoruz

Geliyoruz geliyoruz

Yavaş yavaş alıyoruz

Ergani ciğer dağladı

Nice analar ağladı

Barış pınarı çağladı

Bekle Firat geliyoruz

Geliyoruz geliyoruz

Biz bu işi biliyoruz

Âșık Ergani koçaklamayı söyledikten sonra atıșma için Âș1k Eyyubi ile Maraşlı Öksüz Ozan sahneye davet edildiğinde atışmaya Âşık Eyyubi başlamıştır.

Eyyubi:

Güney doğudan yürüdük

Coştuk barış pınarında

Sınırlarını koruduk

Koştuk barış pınarında

Maraşlı Öksüz Ozan:

Biz doğuştan savaşçıyız

Piştik barış pınarında

Nice aşılmaz dağları

Aştık barış pınarında 
Eyyubi:

Hayal etsin dünlerini

Biliyoruz cinlerini

Terörlerin inlerini

Eştik barış pınarında

Maraşl1 Öksüz Ozan:

Bakın Türklerin önüne

Damardan asil kanına

Bütün devletler önüne

Geçtik barış pınarında

Eyyubi:

Eyyubi der ki biriyle

Komutanıla eriyle

Mehmetçiğin zaferiyle

Şiştik barış pınarında

Maraşl1 Öksüz Ozan:

Geçmişiz uzay çağını

Öksüzüm aştık dağını

Ay yıldızlı bayrağımı

Açtık barış pınarında

Atışma bittikten sonra Âşık Selami Yağar bir şiir okumak üzere sahneye davet edilmiştir. Sahneye çıkan Âşık Selami Yağar da usta malı olan, Ozan Arif'e ait "Coşuyorum Şu Anda" isimli şiirini okumuştur:

Tarifi imkânsız hisler içinde

Kabarıyor coşuyorum şu anda

Turan görünüyor sisler içinde

Yollarına düşüyorum şu anda

Niyet ettim daha yola girmeden

Geçilir mi Nahçıvan'ı görmeden 
Nahçıvan'da bir çay içip durmadan

Bakü'deyim şaşıyorum şu anda

Bakü’de düğümü çözer gibiyim

Sanki İstanbul'da gezer gibiyim

Bakü’yü okşayan hazar gibiyim

Kabarıyor taşıyorum şu anda

Can Azerbaycan'da kabaran yürek

Durmaz artık yolcu yolunda gerek

Ver elini Türkmenistan diyerek

Aşk-1 abadı aşıorum şu anda

Oradan da çıkıp Taşkent yoluna

Semerkant Buhara Özbek eline

Âmuderya olup Aral gölüne

Dolup dolup taşıyorum şu anda

Ben taşarken Tacikistan susuyor

Bişkek'e varmazsam Kırgız küsüyor

Tanrı dağlarında rüzgâr esiyor

Tatlı tatlı üşüyorum şu anda

Üşüsem de gidiyorum öteye

Kirgızistan yani Almaataya

Mazideki gibi binip bir taya

Yesi'deyim koşuyorum şu anda

Çünkü Yesi bir mübarek kucaktır

Ana kucağından daha sıcaktır

Ahmet Yesevi'ye ait ocaktır

O ocakta pişiyorum şu anda

Horasan'ın erleri de piştiler

Anadolu Rumeli'ye düştüler

Orada bir nur bir güneştiler 
Nurlarından içiyorum şu anda

Nurlarından içiyorken işte tan

Gam bürüyor yüreğimi yine gam

Doğu Türkistan'ın Batı Trakya'm

Yaranızı deşiyorum şu anda

Yaral1 yaralı gönül yürüyor

Geri dönüpte Bosna'ya varıyor

Evlad-1 Fatihan şehit veriyor

Mezarını eşiyorum şu anda

Mezar eşmek korkutmuyor beni pek

Ne mezarlar eştim bugüne dek

Kırım'a Musul'a Kerkük'e tek tek

Ay yıldızı döşüyorum şu anda

Ay yıldız örtüsü Kızılelma’nın

Arif doruğunda murat almanın

Ülkücü olmanın bozkurt olmanın

Gururunu yaşıyorum şu anda

Şiirden sonra Âşık Mürsel Sinan türkü okuması için sahneye davet edilmiştir. Mürsel Sinan türküden önce bir şiir okumuştur:

Bana sağc1 solcu deme

Ben vatanın aşı̆̆ıyım

Bu milletin bu devletin

Saf hukukun aşığıyım

$\mathrm{Bu}$ vatanın bu toprağın

Canımdan aziz sancağın

Ay yıldızlı al bayrağın

Alkanının aşığıyım 
Kumandan Mustafa Kemal

Canımız vatana helal

Ya ölürüz ya istiklal

$\mathrm{O}$ atanın aşı ̆̆ıyım

Şiirden sonra şu türküyü okumuş̧tur:

Türkülerdir benim canım cananım

Benim gönlüm türkülere sevdalı

Toprağım harmanım bağım bostanım

Benim gönlüm türkülere sevdalı

Kimisinde Pir Sultan'1n ahı var

Kimisinde Karacaoğlan ruhu var

Baba Şenlik, Sümmâni, Emrah'1 var

Benim gönlüm türkülere sevdalı

Ayşe'nin Mehmed'i gurbete çıkar

Anası ah çeker yollara bakar

Yüreği yandıkça bir türkü yakar

Benim gönlüm türkülere sevdalı

Mürseli Sinan'1m yollara düştüm

Deli Derviş oldum çöllere düştüm

Derdi destan oldum dillere düştüm

Benim gönlüm türkülere sevdalı

Türküden sonra Âşık Binali ile Âşık Kaptani atışma için sahneye davet edilmişlerdir. Sahneye çıkan âşıklar, Âşık Binali Kılıç'ın başlamasıyla şu atışmayı yapmışlardır:

Âşık Binali Kılıç:

Konya'da bir çı̆̆ır açmış

Karatay Belediyesi

Âşıklara kucak açmış

Karatay Belediyesi 
Âşık Kaptani:

Bizi sizlerle buluşturdu

Karatay Belediyesi

Alkış vurup da coşturdu

Karatay Belediyesi

Âş1k Binali Kılıç:

Selam vermiş esen yele

Coşku gelmiş artık tele

İmza atmış en güzele

Karatay Belediyesi

Âşık Kaptani:

Nider deli gönül nider

Mehmetçik zafere gider

Bu kültüre hizmet eder

Karatay Belediyesi

Âş1k Binali Kılıç:

Binali söyler derini

Herkes bilmeli yerini

Kutluyoruz zaferini

Karatay Belediyesi

Âşık Kaptani:

Âş1kKaptani der durur

Mizrabı sazına vurur

İnşallah bu kültür yürür

Karatay Belediyesi

Bu atışmadan sonra Mevlana Meydanı'ndaki program sonra ermiştir.

\section{Yöntem}

Araştırma, metodolojik olarak betimsel, tarihi araştırma yöntemi kullanılarak oluşturulmuştur. Tarihi araştırmalar; geçmişte meydana gelmiş olay ve olguların çok boyutlu incelenip, ayrıntılarının ortaya çıkartılması olarak tanımlanabilmektedir. Ayrıca gözlemleme metoduyla bütün görüntüler kaydedilerek değerlendirilmiştir. 


\section{Bulgular}

Âşıkların bir arya geldiklerinde Türkiye'nin bütün bölgelerindeki olaylardan haberleri olup gündemi takip ettikleri tespit edilmiştir. Şiirlerinde, atışmalarında, güzellemelerinde ve türkülerinde gündemdeki konular açıçca görülmektedir. 53. Âşıklar Bayramında halkın geniş katılımlarıyla kendi kültürlerine sahip çıtıkları görülmüştür.

\section{Sonuc}

Elli üçüncü Konya Âşıklar Bayramı'nın yapılmasıyla süregelen geleneğin devamı sağlanmıştır. Katılım sağlayan pek çok âşık, gelir elde edebilecekleri düzenli bir işe sahip olmadığı için ekonomik zorluklar çekmektedir. Âşıklar Bayramı'na katılımın artırılması için ekonomik şartların iyileştirilmesi gerekmektedir. Türkiye'nin çeşitli yerlerinden âşıkların katılımı olmuştur ancak Konyalı âşıklar daha az katılım sağlamışlardır. Daha fazla katılım için de teşvik edici çalışmalar yapılmalıdır.

Katılan âşıklarımız âşıklığın; divan, atışma, güzelleme, koçaklama, taşlama, şiir, türkü, hikâyeli türkü, lebdeğmez türlerinde örnekler vermişlerdir.

Konya'nın değişik meydanlarında ve Mevlana Kültür Merkezinde yapılan programlara halkın ilgisi hayli yoğun olmuştur. Âşıkların icra ettikleri türleri ustalıkla yapmaları âşıklık geleneğinin sevilmesini ve ilgi görmesini sağlamıştır. Âşılar programlarda kendinden emin hiç heyecan olmaksızın çok iyi bir performans sergilemişlerdir. Birbirleriyle çok iyi bir diyalog ve muhabbet içindedirler. Sazlı, sözlü atışmaları dinlenme salonlarına ve istirahat ettikleri otellere kadar taşmıştır. Türkiye'nin değişik yerlerinden âşıklar arasındaki kardeşlik âdeta tüm Türkiye'nin göstergesi gibi olmuştur. Konya örnek alınarak Türkiye'nin tüm bölgelerinde bu bayramlar çoğaltılırsa bütün bölgelerdeki âşıkların da katılımı sağlanılabilinir. Konya'da düzenlenen bu bayramda Türkiye'nin önemli tavırlarından birisi olan Konya tavrıyla icra edilen bir esere rastlanmamıştır. Âşıklar Bayramı'na ev sahipliği yapan şehrin kendi tavrıyla çalınan eserin yer alması çeşitlilik açısından daha güzel olacaktır.

Âşıkların bu tür buluşmalarıyla beraber yoğun bir katılım sağlanılırsa Türk Edebiyatı'na, Türkülere ve toplum barışına oldukça katkısı olacaktır. Hatta bu bayramların uluslararası bir düzeye taşınmasıyla da Türk Dünyası'nın her yerinden katılım sağlanmasına vesile olunarak kardeşliğin ve birliğin kuvvetlendirilmesi sağlanılabilinir.

\section{Kaynakça}

Gazimihal M.R.(1947),Konya'da Musiki, Ankara, CHP Halk Evleri Yayınları.

Halıcı M. (1985), Konya Sazı ve Türküleri, İstanbul, Özden Matbaacılık.

Kamiloğlu R. (2019), Konya Âşıklar Bayramı Kamera Çekimleri.

Komisyon, (2000), Türkçe Sözlük, Ankara, Türk Dil Kurumu.

Özbek M, Folklor ve Türkülerimiz, (1994), İstanbul, Ötüken yayınları.

Sipahi C. (1975), Türk Halk Oyunları, Ankara, Türk Tarih Kurumu Basımevi. 